\title{
Responding to crisis through strategic knowledge management
}

\begin{abstract}
Purpose: Many managers would like to take a strategic approach to preparing the organisation to avoid impending crisis but instead find themselves fire-fighting to avoid its impact. In this paper we examine an organisation which made major strategic changes to respond to the full effect of a crisis which would be realised over a 2 to 3 year period. At the root of these changes was a strategic approach to managing knowledge. We reflect on the managers' views of the impact this strategy had on preparing for the crisis and we explore what happened in the organisation during and after the crisis.
\end{abstract}

Methodology/ approach: The paper examines a case-study of a financial services organisation which faced the crisis of its impending dissolution. The paper draws upon observations of change management workshops, as well as interviews with organisational members of a change management task force.

Findings: The response to the crisis was to recognise the importance of the people and their knowledge to the organisation, and to build a strategy which improved business processes and communication flow across the divisions, as well as managing the departure of knowledge workers from a dissolving organisation.

Practical implications: The paper demonstrates the importance of building a knowledge management strategy during times of crisis, and draws out important lessons for organisations facing organisational change.

Originality/ value of the paper: The paper represents a unique opportunity to learn from an organisation adopting a strategic approach to managing its knowledge during a time of crisis.

\section{Keywords}

Crisis, change, knowledge management strategy

\section{Category: Case-study}




\section{INTRODUCTION $^{1}$}

One only needs to talk to a range of managers to discover that, in many organisations, strategic thinking and strategic planning are often replaced with fire-fighting and the reliance on emergent solutions (Spence, 1999). This can certainly be the case with knowledge management (KM) where organisations might develop capabilities piecemeal, perhaps before taking a strategic approach (Ruggles, 1998; McCann and Buckner, 2004; Ciabuschi, 2005). However, often the need for a strategic approach (i.e. purposefully aligning initiatives with an organisation’s strategic imperatives) is only realised when looming crisis forces reconsideration of the organisation's current direction,(Collison and Parcell, 2001; Ford and Angermeier, 2004).

The imperatives forcing the need for a strategic approach are obviously wholly contextual. From sixteen organisations we have recently worked with in developing KM strategy (see Edwards and Shaw, 2004; Shaw and Edwards, 2005), the crises which encourage their taking of a strategic view included: becoming swamped with data and being unable to forecast accurately as a result; the merging of three organisations demanded the new organisation to start acting differently; needing process change to remain competitive; retaining essential knowledge during site relocation.

The organisation which is the focus of this paper, the Mortgage Code Compliance Board (MCCB), was faced with a particular kind of crisis - the impending closure of the organisation, driven by legislative changes in the regulatory environment. $\mathrm{MCCB}$ is quintessentially a knowledge organisation and its employees knowledge workers - its regulatory and advisory function relies upon the codification of professional expertise. The importance of the employees' knowledge and the need to manage it effectively was recognised by MCCB and became a strategic central pillar of its organisational change programme. MCCB was forced to take a strategic view of knowledge management because they were closing their operations and a reducing workforce coping with growing stakeholder requirements demanded major changes to sustain operational effectiveness. Over nearly three years these changes required the balancing of three pillars of KM: people, process and technology (Ahmed et al, 2002; Massey et al, 2002). MCCB has now closed and this paper provides a retrospective analysis of how the

\footnotetext{
${ }^{1}$ Please note that some references have been removed in order to anonymise the authors
} 
organisation managed the crisis of closure by assuming a strategically central programme of knowledge management.

Our work with MCCB has been discussed elsewhere (Shaw et al, 2003; Shaw et al, 2006), but this paper adds to these accounts by providing a more critical assessment of the implementation of KM strategy from a new perspective of the senior managers who designed and implemented that strategy and the staff who were affected by these changes.

The structure of the paper is as follows. First, we review the knowledge management literature and consider what constitutes an effective KM strategy. We ask the question 'what happens to knowledge management in a time of organisational crisis?' We then introduce the background to the case study and describe the crisis which encouraged MCCB to take a strategic view of KM. We briefly introduce the methodology used to develop the strategy, before examining the change process and reviewing the actions implemented as part of the strategy. Drawing upon in-depth interviews with members of the KM implementation group, together with observations from workshops and meetings, we discuss how MCCB made its KM strategy central to the change process, and draw conclusions about the role of knowledge management in a time of organisational crisis.

\section{Balancing people, processes and technology}

Due to the breadth of KM activities and the scope of KM practice, there are many conceptions of KM in organisations. Early practice has been criticised for treating KM as the short-term implementation of IT-based projects, with a predominant view of knowledge as little different to information (Swan and Scarborough, 2001; Hislop, 2005).

It is now widely accepted that approaches to KM fall into two distinct perspectives: people-centred and technology-centred (Alvesson and Karreman, 2001; Dueck, 2001; Scarborough and Swan, 2001; Moffett et al, 2003; Handzic and Zhou, 2005). Despite emphasis on the use of IT to mobilise knowledge management practices, there is widespread acceptance that knowledge is inherently personal (Fahey and Prusak, 1998; McDermott, 1999; Coakes et al, 2002), and that IT can only play a limited role. This is expressed most commonly in the concept that knowledge has a tacit dimension 
(Stenmark, 2000; Connell et al, 2003) and only part of a person’s knowledge can be made explicit and articulated as information.

Although IT plays an important role in facilitating the flow of knowledge in organisations, it should support knowledge processes rather than become the predominant focus of KM activity (Alavi and Leidner, 2001). As knowledge is inherently personal, KM initiatives need to focus first and foremost on nurturing the people who have the knowledge, with technology playing a supplementary role (Robertson and O’Malley Hammersley, 2000). Furthermore, the organisation needs to foster appropriate processes by which the knowledge of its individual members can interact for the benefit of the whole organisation (Hammer et al., 2004). Maier and Remus (2003) suggest that a process focus is a way of bridging this apparent dichotomy between the people-oriented and the technology-oriented approaches. However, the business should not nurture business processes whilst stifling that informal knowledge sharing between people by which much organisational work is performed (Brown and Duguid, 2000).

A number of organisations have recognised the balance between people, processes and technology as a framework for organising their knowledge management activity. For example, Massey et al. (2002) discusses the case of the telecommunications firm Nortel Networks, while Ahmed et al. (2002) give the examples of the information systems company ICL and the UK's Post Office organisation. Even if firms do not adopt an explicit people-process-technology framework, there is nevertheless a universal recognition within KM case-studies that an important principle is for firms to nurture an appropriate culture for knowledge management. This is fundamentally a people and process-oriented focus. Black and Decker is one among the many cases in point (Pemberton et al., 2002).

\section{Knowledge management and strategy}

Because KM is such a fundamental activity which impacts upon most areas of the business, organisations need to take an overarching strategic approach to align knowledge management with business strategy, rather than KM existing as random and isolated pockets of activity (Zack, 1999; McCann and Buckner, 2004; Snyman and Kruger, 2004). In knowledge-based firms strategy cannot be treated as an exclusively top-down process, but knowledge workers should be represented and involved 
in strategy formulation in order to generate collective ownership of the process (Carlisle, 2002; Shaw and Edwards, 2005). Because of the increasing importance of knowledge processes as the principal activity of knowledge-based organisations, KM should be embedded in the organisation's working practices and business strategy. While ongoing senior management support for KM plays a critical role, knowledge sharing should be everyone’s concern, not just the occupation of an isolated group or project (Liebowitz, 1999; Storey and Barnett, 2000). Nevertheless, there is an important leadership role to be played in building and sustaining the momentum of any specific KM activity. Jones et al. (2003) refer to this “dual role of expert change agent and knowledge manager” by the term 'knowledge champion'.

\section{Knowledge Management in times of crisis}

Despite the ideal of these principles, the reality of creating and sustaining the momentum of KM in business is often difficult. Storey and Barnett (2000) present a case-study of a firm which is provoked by an external crisis to drop its KM initiative. Although the initiative is central to the need for cultural change in the organisation, and arguably, a deeper and more embedded form of organisational crisis, the firm is forced into a mode of fire-fighting for survival, leading Storey and Barnett to conclude that KM is often seen as a 'nice-to-have' rather than a mission-critical activity. That KM is viewed as a luxury which can be so easily 'dropped' implies it can be viewed as an appendage and not properly embedded into business processes or integrated into organisational strategy.

Roux-Dufort (2000) defines a crisis as “a process of transformation induced by a major disruption that forces the restructuring of social, human and natural systems.” He presents case-studies in which the opportunity for the organisation to learn from a crisis is confounded by its attempt to re-establish the status quo, rather than seeing the crisis as an opportunity to learn and evolve. This is in contrast to Kim (1998), following Pitt (1990), who finds that some firms view crisis as more of an opportunity than a threat. Kim (1998) suggests that there are two types of crisis; those which are proactively constructed by the firm in order to precipitate organisational change, and those which are evoked by the external market, technological or regulatory environment to which the firm must reactively respond. Kim views such times of crisis as episodes in which firms can engage in rapid organisational learning, as in the case of the Korean car manufacturer Hyundai, which invoked a state of crisis in order to transform 
itself from a firm which learned through imitation of foreign manufacturers, to one which was able to generate its own research-led innovation. Thus Kim argues that a state of crisis should not be seen merely as a danger which renders the firm defensive, but as an opportunity for organisational learning.

While organisational crisis and its management has provoked modest interest in the academic literature, interest in knowledge management and learning in times of organisational crisis has attracted even less comment. There have been some interesting papers on organisational learning or the failure to learn from crisis (e.g. Roux-Dufort, 2000; Elliott et al, 2000) and learning about how better to manage the crisis process (e.g. Simon and Pauchant, 2000). However, this paper is not about organisational learning and how organisations learn or fail to learn from crises, it is about what happens to an organisation's knowledge management agenda in such a period of major restructuring. The literature review has suggested that effective knowledge management should be a balanced focus on people, process and technology which features at the core of the firm's strategy. As such a firm's strategic approach to KM should survive an episode of crisis rather than be dropped from the agenda. However, we have been unable to find any empirical research on firms which have incorporated strategic KM into the process of crisis management. While it would appear some organisations are reacting to externally evoked crises while others are proactively generating crisis in order to learn, in both cases there is the implication that the aim of crisis management is to ensure organisational survival. Pearson and Clair (1998) characterise an organisational crisis as a short term episode which has a major threat to the survival of the organisation or its stakeholders, but one which is nevertheless capable of resolution. In this paper we examine a case-study of an organisation facing a type of crisis which has not hitherto been encountered in the research literature - an externally evoked crisis for which the only resolution is the inevitable dissipation of the organisation.

\section{METHODOLOGY}

The paper is based upon a case-study of an organisation in crisis - that of a UK financial services organisation known as the Mortgage Code Compliance Board (MCCB). The data are drawn from a number of sources collected over a three year period, including: 
- Data from three strategy making workshops (each a day long). More on the aims of these workshops are discussed below, but the data collected includes: records from pre-workshop meetings; the model of discussions built during the workshop; computer logs of who shared which opinions; participant feedback on the process and strategy; post-workshop de-brief meetings with the client; final reports of the workshop outcome; a video recording of the third workshop.

- In-depth interviews with five members of the change implementation team (September 2004, MCCB ceased its operations in October 2004). These looked back at the group’s impact on the organisation.

- Documentation collected from MCCB e.g. monthly staff newsletters, the strategy document.

- Details from a web-site set up to support communication among ex-staff following closure.

- Observations made by one of the paper's authors, who worked at executive director level within the case-study organisation during the period of the research.

Findings were discovered by analysing the interview data and allowing themes to emerge through that analysis (Miles and Huberman, 1994). These themes helped us to appreciate and communicate what the participants experienced and felt.

In terms of reflecting on the impact of the actions, there was no use of formal tools such as the balanced score card, or specific key performance indicators against which progress was measured. Instead, there was extensive reflection on the impact of the initiative by the managers who were in the KM Group. Reflection was a fundamental feature of MCCB’s strategic approach to KM as, in monthly progress meetings, reflection was used to assess the impact of recent activities. A major reflective event was a workshop which brought the KM Group together to reflect on their progress and agree next steps. The reflection took the form of considering the progress towards each action and exploring where more effort needed to be placed.

It is important to clarify the role of the authors in the data collection process. Initial contact between the authors and MCCB was through the facilitation of three strategy making workshops (described below). These workshops enabled MCCB to generate its own change management programme, led by a team 
which became known as the KM Group. (More detail about the team will be given in the section "Organising change in MCCB”.) As such the role of the researchers within the change programme was one of facilitation rather than implementation. Design and implementation of the change programme was the exclusive responsibility of MCCB employees. Included in the KM Group was the third author of this paper, who worked in MCCB for 4 years at executive director level and led the change initiative. Although he was a manager at the time of the change programme, the role of this manager as author is to reflect post-hoc on the change process.

The methodology for this research is therefore one of case-study - wherein the authors are drawing upon this organisation as an example of Knowledge Management in times of crisis, and were predominantly passive observers in the change process - rather than one of action research in which researchers adopt a proactive role in implementing change in order to observe its effects. As Eden and Huxham (1996) suggest, it is important not to confuse passive engagement in a case-study of change in an organisation with the more purposeful methodology of action research.

Throughout this paper we make use of quotes from all members of the change implementation team. These quotes are taken from the variety of sources mentioned above.

\section{THE CASE STUDY}

\section{Introducing MCCB}

The UK mortgage market is acknowledged as one of the principal drivers of the UK economy. Prior to the implementation of statutory regulation, under the Government sponsored body the Financial Services Authority (FSA), the industry was regulated by a non-statutory or 'voluntary' code of practice. This was monitored and run by the Mortgage Code Compliance Board - an independent, notfor-profit organisation, funded by registered firms. MCCB had secured near 100\% adoption of the Code amongst trading mortgage firms (lenders and brokers) and had strong powers of enforcement over its registered firms.

MCCB began operations in October 1999 and ceased its activities in October 2004 when responsibilities were assumed by the FSA. Since its inception MCCB knew that closure was inevitable, 
but was uncertain of when this would happen until a Government announcement of December 2001 [the date for statutory regulation to be implemented was then set for October 2004]. This uncertainty contributed to the impact of the crisis, but was also a catalyst for the organisation taking a strategic view of KM.

MCCB was led by an Executive management team of six people, with the senior management group reporting to it. There were two main departments in MCCB. 'Registration Services' (sometimes called 'Administration') managed quantitative data on firms which was collected and updated through a formal annual registration and data capture process. The ‘Compliance Team’ was responsible for acquiring qualitative data from market intelligence and visits to firms. Also, a Helpline function was in place which handled telephone calls about the Mortgage Code from consumers as well as dealing with queries from registered firms.

\section{Framing the crisis}

The crisis to which we refer was spiralling work with which the existing processes would have been unable to cope given the certain gradual diminishing of the workforce. The pressures of work were painfully complemented with the pressures of redundancy, as one employee noted, “it’s been described as the longest death-bed scenario in the world. We have known for three years”. The crisis was accentuated by several factors within the organisation, including (to save space we have limited evidence to one quotation from a manager on the KM Group for each point, but more are available):

\section{Process}

One main factor was the ineffectiveness processes used in MCCB. Information and knowledge was being regularly lost due to the lack of effective capturing processes, for example, it was as simple as telephone calls not being logged: "if we get a call from the public or from Trading Standards or someone, in the past it could have been lost”; or as serious as specialist knowledge not being retained by the organisation: "people were leaving [specialist functions]... taking knowledge ... with them - it wasn’t being recorded”. Some processes which acquired important knowledge were too labour intensive for the dissolving organisation: "we would spend an entire day with the firms collecting data ... half the stuff we could do in paper format a month before we go and see the firm”; and other 
processes lacked coordination across the organisation: "we used to collect data on the understanding it would be useful to other people and then we found it actually wasn’t useful to anybody”. Lack of communication between departments was significant and knowledge was not being shared: "there are cases where Registration were finding things out about firms and not passing it on to Compliance and vice versa. Knowledge was being lost”. The processes in MCCB were complicated by the working environment: "twenty compliance inspectors working from home ... and we also have, the London [Headquarters] office. For a small organization [communication is] quite complex”. In short, the processes were in need of revision which would require cross-functional team collaboration.

\section{People}

The people in MCCB contributed to the looming crisis, in as much as they suppressed their concerns over their working environment: "we all knew what the problems were, but it’s difficult to voice them sometimes”; one reason for which was that departments were in competition with each other, not cooperation: "personality problems with some of the senior management ... at each others throats ... didn’t get on terribly well, which effected communication all the way down the line really”. Problems with communication were physical as well as personal/social: "very much communication problems which were physical because we have an upstairs and a downstairs. Compliance Team is upstairs, Registrations is downstairs and that caused some sort of them and us [atmosphere]”. All this created a working environment from which "people who were very highly marketable ... could be quite easily induced to leave” which would put additional strain on the remaining workforce.

\section{Technology}

Regarding technology and IT training: “we didn’t do much in the way of internal I.T. training where someone who was maybe a specialist in Microsoft Access or Excel, that knowledge wasn't being shared".

Overall, the problem was often summarised to be: "about internal communication ... about sharing knowledge within the job”. 
Potential solutions to the crisis were unclear, largely because of its effect on most aspects of the organisation’s people and processes, less so on technology (discussed later). It was a wide-reaching problem, as one member of the change implementation team reflected about KM, "Imagine travelling to the end of the universe. You can think about it for ten seconds and then you go, 'I can't do that."' Instead of following a fire-fighting approach of dealing with emerging problems piecemeal, MCCB took a strategic approach to planning and implementing a programme of change.

\section{Organising change in MCCB}

To drive change through, a group of eight key MCCB senior staff was formed, drawn from all functions across the organisation. Members of MCCB's Executive management team suggested suitable members for the group, but all those suggested readily volunteered to participate. These eight people "comprised the majority of the senior management group, and included 50\% of the Executive management team". This group was supported by the entire Executive team, and was empowered to make the changes required to achieve its objectives.

Very early in the initiative the group named themselves the KM Group, after the name of the facilitators’ university. Previously we have described the KM Group as a ‘community of implementation' in that it had the aim to "pool individual knowledge (including contacts and ways of getting things done) to stimulate collective enthusiasm in order to take more informed purposeful action for which the members are responsible” (Shaw et al ${ }_{\longrightarrow}$ 2006). The KM Group regarded its scope to be “very much that it wasn’t our responsibly to ensure that [progress] happened. It was to provide the catalyst for the company to actually achieve those things themselves”. It is clear that the members of this group therefore met the Jones et al. (2003) definition of 'knowledge champions', since they were acting both as knowledge managers and as agents of change. Jones at al. emphasise the need for knowledge champions to link various groups of people within an organisation, including innovators, opinion leaders and "users" (of knowledge).

Core to the strategic thinking of the KM Group were three workshops. 
- Workshop 1 (June 2002) aimed to uncover the magnitude of the crisis and explore a range of potential high-level solutions as well as begin to gel the group with the view of them being responsible for taking action to address the problems.

- Workshop 2 (September 2002) aimed to: narrow the range of tasks from Workshop 1 which would be tackled onto those which would deliver most organisational benefit; allocate individuals to working on these tasks; bond the group into a tighter working unit.

- Workshop 3 (October 2003) aimed to: reflect on progress since Workshop 2; discuss barriers to progress; explore the impact of actions on MCCB; identify actions for the remaining period.

Between each workshop the KM Group held monthly progress meetings. These meetings aimed to: monitor progress of actions against targets; support the members in overcoming problems being encountered; strategise how to have most impact on the organisation; agree publicity of the KM Group and its progress. Members of the group volunteered to take actions in specific 'project' areas, and all actions had at least two members being responsible for their delivery (to ensure accessible support was readily available). As mentioned earlier, all members were senior managers, but it should be noted that before the formation of the KM Group they had no prior experience either of formally carrying out “knowledge management” or of being responsible for it.

\section{The actions}

The contribution of this paper is a retrospective assessment of the impact of knowledge management strategy on organisational learning, not a discussion of what was implemented in MCCB. The detail of the actions have been discussed elsewhere (Shaw et al., 2003; Shaw et al., 2006), but need to be briefly reviewed here to set the scene for reflecting on their impact.

A limiting feature of the action plan was that actions must be completed at minimal cost within 6 months because “There is no point in setting out a project which isn't going to gestate in anything longer than six months. If we only have a two-year life what's the point of having a two-year project. We won't get any benefit from it”. 
The KM Group had five main strategic objectives. There were self-defined, but had executive sanction, and included:

1. To improve employees' skills with the aim of benefiting MCCB, retaining staff and improving their personal marketability following closure. [Rolled out by April 2003, running to closure.]

2. To build skills contingencies with the aim of retaining key knowledge. [In place by November 2002, rolling out intensively to April 2003, activities running to closure.]

3. To improve internal communication structures. [Start immediately, running to closure.]

4. To improve the personal working environment with the aim of motivating people not to leave before closure. [Start immediately, running to closure.]

5. Process improvement with the aim of reducing input whilst maximising output. [Rolled out by April 2003, running to closure.]

The first four of these focus on knowledge retention, while the fifth explicitly centres on process efficiency.

To address these five objectives, the KM Group designed seven projects. The projects were described in MCCB's staff newsletter as:

1. Contingency planning to retain knowledge and skills of staff in key roles. [In place by November 2002, rolling out intensively to April 2003, activities running to closure.]

2. A retention strategy to encourage staff to stay to the end and help them to prepare for the future. [Strategy in place by November 2002, rolling out intensively to April 2003, activities running to closure.]

3. Build an open and supportive working environment to encourage teamwork. [Start immediately, activities running to closure.]

4. Improve processes through continuous improvement. [Rolled out by April 2003, running to closure.]

5. Sharing knowledge of each other's roles. [Start immediately, running to April 2003.]

6. Create a sense of belonging to the same organization. [Start immediately, running to April 2003].

7. Using existing software more effectively. [Start by November 2002, rolling out to April 2003]. 
Each project included a number of inter-linked activities. To give a flavour of these activities, we briefly note that these included: audit of computer-skills; arrange tailored training sessions (e.g. IT, presentation skills, CV writing); document work processes; rationalise business processes; organise job rotation and training in critical roles; provide 'awareness' training of roles across functions; improve cross-functional communication through formal meetings and informal social activities; introduce new processes for sharing knowledge, agreed service standards between departments. All of these actions aimed to address particular components of the seven projects, most addressing a number of components on a range of projects.

\section{REFLECTING ON THE CHANGE}

The paper will now reflect on, from the perspective of members of the KM Group, the change implemented in MCCB. These reflections were amassed from individual interviews with each KM Group member and are presented below in terms of: the impact of actions; the implementation of actions; progress since cessation of the KM Group.

\section{Reflecting on the impact of actions}

In the third workshop the group felt that $85-90 \%$ of the original actions had been implemented (see Shaw et al. 2006 for what this involved). However, this percentage estimate fails to convey the effect these actions had on the organisation. The following, more insightful reflective account reviews the effect of these actions, from the perspective of those who implemented the change and were affected by it.

The projects had positive implications on the causes of the crisis - again clustered around process, people and technology.

\section{Process}

Considerable attention was given to the processes, by management and the users of the processes. Part of this focused on reviewing the worth of processes and improving their usability given a reducing workforce: “people were encouraged to say, ‘what do you do within your job that we don’t actually 
need to do'. Right, can we cut one or two of those out? Can we do [that] in a different way? So it's certainly continuous improvement but it's another way of it", "Streamlining processes has improved ... [we were collecting useless] data, so why collect it? Why waste our time?”. This effort led to a more efficient use of time: “[using our new Intermediate Compliance Questionnaire] you can do an audit within two hours from a desktop, issue a relatively accurate report without the need to [as we used to] spend a day travelling, a day with the firm, a day writing the report”; and also led to sharing knowledge across departments because the process users were becoming used to talking to each other about business activities: "whilst we have data and they have data, we never used to openly go and ask each other about it or share it. The workshops, the KM Group work has certainly blown that away”, "we now say, 'Registrations need to be aware of this,' [and] we'll get some [information] from Registrations that helps us".

Another part of process improvement involved a skills audit to: "identify what everyone did, what was the process and who had that knowledge. Then [built] a matrix to see [what would happen] if that person left ... and set up a training course where we want at least three people to have that skill and knowledge". This exercise also captured key process knowledge "we went through the [task] of creating procedure manuals and we almost did a competency exercise and, as a result of knowing an awful more about ourselves, we decided to try to do as much cross-training as possible”. The result was the ability to identify key areas of risk and build contingency to sustain the organisation if/when key individuals left.

The building of skills contingency had two levels of intensity - awareness training and fully competent training. Awareness training aimed to show staff how roles fit into the organisation: "Someone from upstairs would go downstairs for the day. Someone downstairs will go upstairs and [we learned] what they do with information that is passed upstairs or was on the database” which successfully "[gave us] a far greater appreciation of ... what roles were performed in other parts of the business ... not only what they do [but] why they do it and why they do it in a certain way”. In certain areas MCCB trained individuals to be fully competent in core tasks to retain specialist knowledge and skills: "they swapped jobs so that they could actually do the job of another person within the same department ... so that if somebody were to leave then there would be a second and a third person who was actually able to do 
that one job”. Part of this was done through: "job rotation has been hugely successful, because we are seeing the benefits of that now - now people are leaving ... people are being able to slot into their roles”. This allowed wider recognition of knowledge needs in other parts of the business as well as helped form closer working relationships across the organisation.

The enhanced personal working arrangements, staff training, and broader awareness of other processes in the organisation allowed MCCB to begin to share resources across departments and thus respond to work pressures: "we have been quite seriously understaffed at times. But that has been overcome because there has been training undertaken to make sure that the rest of the staff downstairs are able to ... give cover [to other functions]”.

\section{People}

Attention to the people dimension was particularly important given the nature of relations in MCCB. The closer working arrangements fostered by a focus on process improvement began to breakdown barriers, encouraged by openly discussing internal relations: "people openly said, yes, there is a problem ... it was as though like a barrier had been moved"; "we had overcome quite a lot of the problems with communication between the two halves of the company. I think that was already being broken down having been brought out into the open and discussed”. Instead of competition, the two main departments began to cooperate, an aspect requiring a change of mindset: "If we interacted better or more fully then MCCB would benefit, so once this concept was introduced I encompassed it wholeheartedly"; "[the initiative] certainly enhanced the co-operation within the building here. In the last year the relationship between [functions] are so much smoother”.

From meeting the colleagues and learning about others roles, people had some common interests which led to corridor conversation and improved communications: "conversations took place whilst you were making a cup of tea or whilst you were walking through the place. Whereas before that conversation either didn't take place or there was no work content in that conversation. So I could ask you how we felt things were going in your area, knowing what you did and vice versa”. This helped to unite the workforce: "it brought us closer together, talking more about things"; as well as helping to improve the effectiveness of the organisation because people were talking to each other: "the bookkeeper went 
down and spoke to the Registration team about the way they processed information that came up to us, and she was able to help the flow of information between the two departments”. Overall there was a closer working arrangement between the people in MCCB and this led to additional process improvements: “[an] investigator ... became very much more involved in the checks that they are doing downstairs and helping them, giving them guidance”.

Another aspect to the people dimension was investing in staff to retain them: "Staff development has been uppermost in the last two or three years. There is hardly anybody who is not studying for something ... everybody has grown enormously”. The notion was to incentivise people to stay by increasing their marketability: "we encourage people to acquire more skills ... We said, you do what you want and we'll pay for it, and a lot of people have taken that opportunity [six examples were provided]”.

\section{Technology}

The focus in MCCB was on people and process, but on technology the main focus was identifying IT training needs and then providing as required: "We did the I.T. literacy survey, where we asked people where they felt they were at, in the sense of finding who can do the training and also seeing how good or bad people’s skills in Word, Excel etc were”. This led to the targeted provision of IT training: "improving users awareness of available software and also improving their skills in a range of applications”.

Many cross-functional social activities were also organised, and an innovative private 'networking' website (an Extranet) was developed to allow staff to maintain contact following closure.

Despite the many successes, one member of the KM Group thought they could have achieved more: "I think some would say, yes [we achieved what we aimed to]. Others are aware that perhaps they didn't push quite as hard as they might have done. But I would say, on the whole, that people felt that there were positive benefits that came out of the exercise”. Another thought “progress was made. I don’t think it was $100 \% ”$ 
Overall, in terms of measuring the effect on the organisation, "it's softer benefits to come out of it rather than saying we achieved savings of $£ 500,000$. It generally improved communications in a sense that we belong to the same organization and we are trying to achieve the same things”. Furthermore, due to tackling the crisis strategically, the initiative "has enabled MCCB to remain fully effective in its operations despite the impact of change and uncertainty experienced in the period to closure”.

\section{Reflecting on the implementation}

Taking a strategic approach was acknowledged as being instrumental in the progress of the KM Group. In addition to the points above which are indicative of the benefits of a strategic approach, participants commented on the importance of being prepared by planning ahead: "the fact that we were already thinking about this two years ago was an enormous advantage ... 'Yes, people are going to leave. What are we going to do? We're not going to just tackle [it by] fire-fighting'”.

There was a strong need for everyone in the organisation to understanding the aims of the initiative and its potential impact on them. Reflecting upon the transfer of skills project in the administration department, a senior manager commented on the need to sell the benefits to those affected by change:

"12-18 months ago I said to everybody that this is what we are going to do and [outlined the] benefits".

MCCB identified their aims and actions using our workshop approach, but other forms could be equally as effective: "[as a result of the Aston ] exercise, that wonderful tool, helped us actually to understand gravely what was needed”. The Aston workshop was a major beginning to closer relationships at a management level: "it was a very valuable experience in communication in actually bringing together management ... to discuss issues and actually focus on things that weren't day to day operational matters but more communication and staff development issues”. It also allowed the management to build motivation: "just as a result of those two workshops a group of people did something about it. It was very, very useful”; and that motivation was targeted on implementing agreed actions which would have significant impact on the organisation: "we obviously all agreed that these were things worth working on”.

\section{Reflecting on progress since the cessation of the KM Group}


The KM Group meetings stopped soon after the third workshop. Reasons for this have been given as "it’s all about plugging the gaps ... so we can just crawl our way until [closure]" and "redundancy has proved a bit of a distraction”.

This cessation of the KM Group brought a cessation in taking a strategic approach to KM, “we’ve stopped thinking strategically now, we're looking more at a fire-fight situation. Operational issues on a daily basis, not even thinking beyond that”.

There were varying views of whether there had been slippage on the issue of communication between the last workshop (September 2003) and the interviews (October 2004). While some thought communication had worsened: "Some things have gone backwards probably ... the, them and us", others thought communication was still good: "for the last twelve months we have seen the benefits of people talking more openly and being more aware of what is going on in different areas of the firm"; "I think communication is generally better".

Up to closure, benefit was still being realised from the initiative: "probably without [this change] happening we wouldn't be in the relatively comfortable position we are. There is still relatively good morale ... because the groundwork was done”

Following closure, the extranet website (which was set-up to facilitate communication after closure) was being actively used by a majority of ex-employees, both for group communication and one-to-one contacts. Five months after closure a social activity was organised through the website. Feedback was that "both Compliance and Registration [were] well represented".

\section{DISCUSSION}

MCCB was clearly facing a unique crisis which has not hitherto been encountered in the research literature. Following Pitt’s (1990) and Kim’s (1998) distinction between crisis which is internally or externally evoked, the crisis faced by MCCB clearly falls into the latter category. The impending closure of MCCB was an externally-evoked crisis driven by statutory changes in the regulation of the mortgage industry. The case is notable for embracing a strategic approach to knowledge management 
in such circumstances. This is in direct contrast to the case presented by Storey and Barnett (2000) of the international consulting firm which abandoned its knowledge management initiative when crisis in the industry forced the firm to restructure. In contrast MCCB has used KM as a response to crisis. The case shows that for knowledge-based firms such as MCCB, the management of knowledge is essentially what the firm does, and as such, knowledge management and business strategy should be inseparable (Zack, 1999; McCann and Buckner, 2004; Snyman and Kruger, 2004). MCCB took an holistic approach to its knowledge management strategy, identifying the deficiencies in the attitudes of its people and the processes by which their knowledge interacts, then designing a comprehensive and organisation-wide solution.

It is interesting in this respect that when the KM Group embarked upon the course of crisis response, they did not recognise it to be an exercise in strategic knowledge management, but over time realised that what they were doing effectively was KM. In looking at the list of activities and the impact they have had, readers also may not recognise the role of $\mathrm{KM}$ in, for example, more efficient use of time, sharing resources, or training. Taking the example of training, the Group came to view this as a KM activity because it involved:

- identifying critical knowledge-intensive activities for which there could potentially be a skills shortage

- building a skills matrix to find out who could cover these key activities, and who had the knowledge (and training skills) to train others

- designing MCCB-relevant training sessions which targeted knowledge-intensive activities

- multi-skilling staff to enable them to cover tasks when people left

- using knowledge already in the organisation

Thus, it was not that KM was used as an umbrella term under which all the businesses activities sought refuge. Instead it was that the Group decided that the core problem and/or solution to these issues depended on better knowledge management. This was an inherent recognition that MCCB is essentially a knowledge organisation within which all business activities depend upon the effective sharing and managing of knowledge.

What features of the case make this a good example of strategic knowledge management?

Deleted: may be a result of the view that $\mathrm{KM}$ arose from the confluence of numerous existing business activities and thus it is possible to identify the role of KM in most activities. 
Carlisle (2002) and Shaw and Edwards (2005) recommend that knowledge management cannot be imposed from the top-down, but that a representative group should be mobilised to generate collective 'bottom-up' ownership of strategy formulation. In the MCCB case, a collective understanding of the problems, and a shared sense of motivation to work towards a common solution, were critical features of a strategic approach. There were however limitations in the extent of representation within the KM Group: First, no on-the-road based member of the Compliance Team was included in the project team, although an office-based manager represented this community. This may have limited ownership and understanding of the project objectives and outputs, despite attempts to address this at regular team meetings and through communication methods such as the newsletter and e-mail updates. Second, although one of the key success criteria - to overcome the lack of understanding and mistrust between the two main departments - was achieved at an operational level, conflict persisted between two senior managers. This may have been reduced by the integration of both senior managers described within the KM Group.

The KM Group acted as the 'knowledge champions' (Jones et al., 2003) responsible for building and sustaining the momentum of the KM strategy. This was evident when momentum declined following the cessation of the project team. Nevertheless it was clear that some fundamental shifts in attitudes and working processes had been embedded as lasting changes: the knowledge champions had helped to institutionalise relevant knowledge. Certainly the effect of the change was deemed to have prepared the organisation for closure.

The effective alignment of KM and business strategy requires the support of top management (Storey and Barnett, 2000). The importance of CEO-support is particularly well illustrated in the case of Buckman Labs (Liebowitz, 1999). In the MCCB case, the CEO was very supportive of the project and promoted it at every opportunity. However, he was not part of the KM Group and only attended one meeting and none of the workshops. Arguably, this may have weakened the group as regards the status of its championing KM within the organisation, but there is no suggestion in the work of Jones et al. (2003) that the CEO personally has to be a knowledge champion. 
Effective communication and publicity of the KM initiatives was a key means by which the KM Group were able to have impact on the organisation. Many of the actions were staff-centred and publicity was a means of engaging staff with the initiatives. This engagement involved encouraging staff to: feed into the design of the actions to improve KM; contribute to the initiatives, perhaps as trainers on courses or helping in action implementation; share good practice; participate in the new esprit de corps which the initiative was building between departments. Publicity was mainly through staff briefings, promoting activities organised by the KM Group (e.g.training sessions, social activities), acknowledgments in Executive level meetings (which fed through to staff via the minutes), and the staff newsletter (which was edited by the leader of the KM Group).

The features discussed above all illustrate how MCCB recognised the importance of fostering a culture for knowledge management to thrive. There are many examples in the literature which emphasise the need to have an appropriate culture for knowledge management to succeed (e.g. Liebowitz, 1999; Hammer et al., 2004). Many of MCCB’s initiatives sought to remove psychological and physical barriers to communication in order to encourage collaborative sharing of knowledge and resources. As in the case of Nortel Networks (Massey et al., 2002) and ICL (Ahmed et al., 2002), MCCB prioritised initiatives for people to develop and share their knowledge, and developed the working processes by which this could happen. There was, however, a limitation in the linking of project objectives to formal appraisal processes and the organisation's business plan. This was seen as a missed opportunity for institutionalising a KM strategy within the organisation.

In MCCB, the emphasis on people and process dominated the approach to strategic management, while technology played a supporting role. This is consistent with other studies which demonstrate an effective balance between people, processes, and technology in knowledge management (e.g. Pemberton et al., 2002; Edwards and Shaw, 2004). In the MCCB case, making better use of existing technology through training staff was the main focus here, for two reasons: (1) MCCB had enough technology that it already did not use well, and it did not want more; (2) buying and implementing new technology would probably fail to satisfy the 'within 6 months, low cost' limitation. Interestingly, rather than source external trainers, MCCB made the strategic decision of "identifying those who can or wish to be trainers in each application and [then] design the appropriate courses for training”. This 
aimed to tailor training courses more than an off-the-shelf provider would as well as give

knowledgeable and willing individuals the opportunity to develop as trainers.

\section{Reflecting on the impact of strategic knowledge management}

Although this is not a paper about organisational learning per se, it nevertheless raises some interesting issues related to organisational learning. The crisis faced by MCCB provoked necessity to engage in strategic knowledge management, and precipitated what we might call ‘learning by imperative.’ Here a climate of learning about each other - as well as about processes, customers, department cultures, roles and responsibilities, causes of friction, new tasks and undertaking further training - permeated the entire organisation,

The prior knowledge base was extensive and immediately available while the staff still worked in the organisation. The wealth of process knowledge that had been accumulated during the three years before the initiative began could be harnessed, as was there a wealth of knowledge of the culture which had to be overcome. Improving communication was key. This enabled the staff across departments to address process weaknesses collectively and work while understanding the importance of their task in the wider process. Communication, and developing a more personal feeling of kinship, was critical in addressing the cultural problems, in particular the friction across the two main departments.

The intensity of effort was apparent through the momentum of the KM Group, the regard with which the organisation viewed that group's success, the internal publicity of the initiative, the affect of the effort on each employee's working life and the rapid implementation of a large proportion of the actions. Through intense effort, a few key individuals infected most of the organisation with a desire to change which had real impact. The looming crisis was a key driver of intensity.

Interestingly much of the reflection on impact was focused on the internal matters and operational efficiencies. The organisation fully achieved its corporate objectives of maintaining robust industry regulation and consumer protection and facilitating transition to statutory regulation. This was recognised by the UK Government Minister with responsibility for financial services markets, by senior industry and consumer figures and in the relevant trade and consumer media. 
Some KM Group members perceived that the third workshop began the demise of the KM Group as they viewed that they had accomplished nearly all of their tasks and had avoided a large proportion of the threat of the crisis. After this workshop much of the enthusiasm seemed to be turned towards operational matters and the impact of redundancies rather than furthering the work of the KM Group.

\section{CONCLUSION}

The lessons from MCCB demonstrate the strategic centrality of knowledge management to an organisation in a time of radical change. There is little precedent for an organisation pursuing such a vigorous and successful knowledge management initiative amid the dissipation of the organisation. MCCB received widespread praise from its industry, trade and consumer media and from Government for maintaining its operational effectiveness and managing a successful transition to statutory regulation.

Within MCCB, "the effort made in establishing the KM Group and taking it forward was certainly seen as justified even though a diminishing workforce created additional pressures as the organisation’s lifespan became ever shorter”. Justification is in terms of improving the effectiveness of the organisation through internal communication and process enhancements across all functions particularly between Registration Services and the Compliance Team. This meant that information on registered firms was more readily captured and shared, and the overall project enabled MCCB to remain fully effective in its operations despite the impact of change and uncertainty experienced in the period up to closure.

As the ex-CEO of MCCB said: "In most organisations inevitable closure and full redundancies would have led to major crisis, reduction in organisational standards, loss of morale and possible organisational collapse. I am pleased that such a scenario was avoided at MCCB - indeed operational efficiencies, standards, workloads and staff loyalty and satisfaction all increased over the period. We fully met our corporate objectives and the expectations of our very diverse stakeholders. The strategic 
approach adopted by the 'KM Group’ and its work in focusing on knowledge management, business processes, service delivery, managing change, enhancing internal communications and concentrating on people issues was undoubtedly one key factor for us during this successful final period.” 


\section{References}

Ahmed, P., Lim, K. and Loh, A. (2002), Learning through knowledge management. ButterworthHeinemann, Oxford, UK.

Alavi, M. and Leidner, D. (2001), “Knowledge management and knowledge management systems: Conceptual foundations and research issues.” MIS Quarterly, 25(1), 107-136.

Alvesson, M. and Karreman, D. (2001), “Odd couple: Making sense of the curious concept of knowledge management.” Journal of Management Studies, 38(7), 995-1018.

Brown, J. and Duguid, P. (2000), “Balancing act: How to capture knowledge without killing it.” Harvard Business Review, May-June, 73-80.

Carlisle, Y. (2002), “Strategic thinking and knowledge management.” In Little, S. Quintas, P. and Ray, T. (Eds.) Managing knowledge: An essential reader. Sage, London, UK, 122-138.

Ciabuschi, F. (2005), “On IT systems and knowledge sharing in MNCs: A lesson from Siemens AG.” Knowledge Management Research \& Practice, 3(2), 87-96.

Coakes, E., Willis, D. and Clarke, S. (Eds.) (2002) Knowledge Management in the SocioTechnical World: The Graffiti Continues. Springer Verlag, London.

Collison, C. and Parcell, G. (2001), Learning to Fly: Practical Lessons from One of the World's Leading Knowledge Companies. Capstone, Oxford, UK.

Connell, N.A.D, Klein, J.H. and Powell, P.L. (2003) “It's tacit knowledge but not as we know it: Redirecting the search for knowledge.” Journal of the Operational Research Society. 54(2) 140152

Dueck, G. (2001) "Views of knowledge are human views". IBM Systems Journal, 40(4), 885-888.

Eden, C. and Ackermann, F. (1998), Making Strategy: The Journey of Strategic Management. Sage, London, UK.

Eden, C. and Huxham, C. (1996), “Action research for management research.” British Journal of Management, 7(1), 75-86.

Edwards, J. and Shaw, D. (2004), “Supporting knowledge management with IT.” In Meredith R., Shanks, G., Arnott, D. and Carlsson, S. (Eds.) Decision Support in an Uncertain and Complex World: Proceedings of the 2004 IFIP WG8.3 International Conferences on Decision Support Systems DSS2004. Monash University, Tuscany, Italy, 233-242. 
Elliott, D., Smith, D. and McGuinness, M. (2000). Exploring the failure to learn: Crises and the barriers to learning. Review of Business, 21(3/4),17-24.

Fahey, L. and Prusak, L. (1998), “The eleven deadliest sins of knowledge management.” California Management Review, 40(3), 265-276.

Ford, R. and Angermeier, I. (2004), “Managing the knowledge environment: a case study from healthcare.” Knowledge Management Research \& Practice, 2(3), 137-146.

Hammer, M., Leonard, D. and Davenport, T. (2004), “Why don’t we know more about knowledge?” MIT Sloan Management Review, 45(4), 14-18.

Handzic, M. and Zhou, A. Z. (2005) Knowledge management: an integrative approach. Chandos Publishing, Oxford.

Hislop, D. (2005), Knowledge management in organizations: A critical introduction. Oxford University Press, Oxford, UK.

Jones, N., Herschel, R. and Moesel, D. (2003), “Using knowledge champions to facilitate knowledge management.” Journal of Knowledge Management, 7(1), 49-77.

Kim, L. (1998), “Crisis construction and organizational learning: Capability building in catching-up at Hyundai motor.” Organization Science, 9(4), 506-521.

Liebowitz, J. (199), “Key ingredients to the success of an organization’s knowledge management strategy.” Knowledge and Process Management, 6(1), 37-40.

Maier, R. and Remus, U. (2003), “Implementing process-oriented knowledge management strategies.” Journal of Knowledge Management, 7(4), 62-74.

Massey, A., Montoya-Weiss, M. and O’Driscoll, T. (2002), “Knowledge management in pursuit of performance: Insights from Nortel Networks.” MIS Quarterly, 26(3), 269-289.

McCann III, J. and Buckner, M. (2004), “Strategically integrating knowledge management initiatives.” Journal of Knowledge Management, 8(1), 47-63.

McDermott, R. (1999) "Why information technology inspired but cannot deliver knowledge management". California Management Review, 41(4), 103-117.

Miles, M. and Huberman, A.M. (1994), Qualitative Data Analysis: An Expanded Sourcebook. Sage, Thousand Oaks, CA. 
Moffett, S., McAdam, R. and Parkinson, S. (2003) "Technology and people factors in knowledge management: an empirical analysis." Total Quality Management \& Business Excellence, 14(2), $215-224$

Pearson, C. and Clair, J. (1998). Reframing crisis management. Academy of Management Review, 23(1), 59-76.

Pemberton, J., Stonehouse, G. and Francis, M. (2002), “Black and Decker - towards a knowledgecentric organization.” Knowledge and Process Management, 9(3), 178-189.

Pitt, M. (1990), “Crisis modes of strategic transformation: A new metaphor for managing technological innovation.” In Loveridge, R. and Pitt, M. (Eds.)d The strategic management of technological innovation. Wiley, Chichester, UK, 253-272.

Quintas, P. (2002), “Managing knowledge in a new century.” In Little, S., Quintas, P. and Ray, T. (Eds.) Managing knowledge: An essential reader. Sage, London, UK, 1-18.

Robertson, M. and Hammersley, G. (2000), “Knowledge management practices within a knowledgeintensive firm: The significance of the people management dimension.” Journal of European Industrial Training, 24(2/3/4), 241.

Roux-Dufort, C. (2000). Why organizations don’t learn from crises: The perverse power of normalization. Review of Business, 21(3/4), 25-30.

Ruggles, R. (1998), “The state of the notion: Knowledge management in practice.” California Management Review, 40(3), 80-89.

Scarbrough, H. and Swan, J. (2001) "Explaining the diffusion of knowledge management: The role of fashion". British Journal of Management, 12(1), 3-12

Scarbrough, H., Swan, J., Laurent, S., Bresnen, M., Edelman, L. and Newell, S. (2004), “Project-Based Learning and the Role of Learning Boundaries.” Organization Studies, 25(9), 1579-1600.

Shaw, D. and Edwards, J. (2005), Building user commitment to knowledge management strategy. Information and Management, 42(7), 977-988.

Shaw, D., Edwards, J., Baker, B. and Collier, P. (2003), “Achieving closure through knowledge management strategy.” Electronic Journal of Knowledge Management, 1, 197-205.

Shaw, D., Baker, B. and Edwards, J. (2006), “Communities of implementation.” In Coakes, E. and Clarke, S. (Eds.) Encyclopedia of Communities of Practice in Information and Knowledge Management. Idea Publishing, London, UK, 35-42. 
Simon, L. and Pauchant, T. (2000). Developing the three levels of learning in crisis management: A case study of the Hagersville tire fire. Review of Business, 21(3/4), 6-11.

Snyman, R. and Kruger, C. (2004), “The interdependency between strategic management and strategic knowledge management.” Journal of Knowledge Management, 8(1), 5-19.

Spence, L. (1999), “Does size matter? The state of the art in small business ethics.” Business Ethics: A European Review, 8(3), 163-174

Stenmark, D. (2000), “Leveraging tacit organizational knowledge.” Journal of Management Information Systems, 17(3), 9-24.

Storey, J. and Barnett, E. (2000), “Knowledge management initiatives: Learning from failure.” Journal of Knowledge Management, 4(2), 145-156.

Swan, J. and Scarborough, H. (2001), “Editorial.” Journal of Information Technology, 16, 49-55.

Zack, M. (1999), “Developing a knowledge strategy.” California Management Review, 41(3), 125-145. 